\title{
EXPERIMENTAL STUDY OF CONCRETE PREPARED BY THE ADDITION OF HUMAN HAIR AND COCONUT FIBER
}

\author{
DIPSHI KAPOOR $^{1} \&$ NIRBHAY THAKUR ${ }^{2}$ \\ ${ }^{I}$ Post Graduate Student, Department of Civil Engineering, Chandigarh University, Mohali, Punjab, 140413, India \\ ${ }^{2}$ Assistant Professor, Department of Civil Engineering, Chandigarh University, Mohali, Punjab, 140413, India
}

\begin{abstract}
Fibers are known to be the best additive material in concrete when it comes to the increment in properties like flexural strength, tensile strength, etc. This paper gives a brief about the work done with two fibers i.e human hair and coconut coir fiber in the concrete to make an increment in the mechanical properties of concrete. The fibers are taken in the same ratio for the addition in the concrete. The ratios introduced in the concrete were 1\%, $1.5 \%$, and $2 \%$. From all, the addition maximum increment was found with $1.5 \%$ which was $17 \%$ in the mechanical properties of concrete.

KEYWORDS: Human Hair, Coconut Coir, Mechanical Properties, Natural Fiber
\end{abstract}

Received: Jun 09, 2020; Accepted: Jun 29, 2020; Published: Jul 17, 2020; Paper Id.: IJMPERDJUN2020371

\section{INTRODUCTION}

Fibers are used both as alternatives and as additional material by researchers to increase properties of concrete. Some of the most commonly used are coconut, human hair, jute, date, different types of leaf, cotton fiber, sugarcane fiber, etc. Coconut fiber is obtained by the outer shell of a coconut. This fiber is of two types of brown fiber and white fibre which are extracted from mature coconut and immature coconut respectively. On the other hand, human hairs are also used in concrete to study different parameters. Fiber strands are utilized in concrete on account of the properties they force yet on the off chance that we talk about human hair, specifically, they are utilized as a result of their high elasticity which is equivalent to that of copper wire with a comparable diameter to reduce environmental problems caused in their decomposition. This fiber is also available in abundance and at a very low cost.

Numerous investigations were performed to comprehend the properties of fiber and its usefulness in concrete. A work by Auda MIorpenda et. al. researched the morphological and hardness qualities of CCHPRC after submersion in $\mathrm{H} 2 \mathrm{SO} 4$ answer for 3, 6, and 9 days. The significant ends were that the 3PA, 6PA and 9PA examples demonstrated fiber pull-out propensities which showed a progressive material corruption and poor grip among coir and polyethylene network. The EDS estimation demonstrated an expansion and decline in the oxygen band, which is characteristic of the development of a slim oxide film at the fiber/polymer interface. Additionally, all the zones of the spectra compared to the polymers in which the band relating to carbon significantly expanded and diminished. These imply that the high oxygen band may have diminished the carbon band for 3PA examples which thusly decreased its hardness, and expansion in carbon groups along these lines expanded hardness esteems for 6PA and 9PA examples. (Auda et al., 2019). 


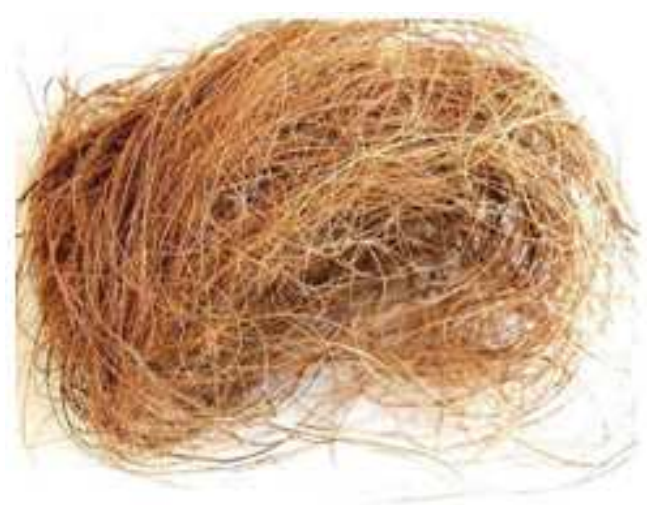

Figure 1: Coconut Coir.

The tests on rope elasticity and rope-CFRC bond quality performed by Ali et. al. uncovered that slight (18 mm distance across) ropes had higher rigidity than that got with medium $(27 \mathrm{~mm})$ and thick (36 mm) ropes. In any case, a higher tractable burden was required for thick ropes contrasted with slim and medium ropes. Thick ropes had more prominent prolongation than that acquired with the slim and medium ropes. Contrasted with the dousing treatment, the elasticity, and stretching of the ropes expanded by bubbling treatment and diminished by compound treatment. The bond quality diminished by $11 \%$ and the draw out vitality expanded by $44 \%$ with an expansion in implant length from 100 to $200 \mathrm{~mm}$. The bond quality diminished by $27 \%$, and pullout vitality expanded by $28 \%$ with an expansion in rope distance across from $18 \mathrm{~mm}$ to $36 \mathrm{~mm}$. The bond quality and pull-out vitality expanded by $41 \%$ and $35 \%$, separately, when the fiber content was expanded from $0 \%$ to $1 \%$. The bond quality and the draw out vitality expanded by $90 \%$ and $52 \%$, individually, when the blend configuration was changed from 1:4:4 to 1:2:2. The bond quality and pull-out vitality diminished by $24 \%$ and $25 \%$, separately, with concoction treatment and expanded by $15 \%$ and $13 \%$, individually, with bubbled ropes contrasted with the drenched ropes.(Ali \& Chouw, 2013).

At the point when M-15 cement with $1 \%$ hair is contrasted and the plain concrete solid, found that there is an expansion of $10 \%$ in compressive quality and $3.2 \%$ in flexural quality, with $1.5 \%$ hair there was an expansion of $22 \%$ in compressive quality and $8.6 \%$ in flexural quality. At the point when M-20 cement with $1.5 \%$ hair is contrasted and the plain concrete, Jain D. and Kothari A. discovered that there is an expansion of $8.8 \%$ in compressive quality and $5.5 \%$ in flexural quality. At the point when M-25 cement with $1 \%$ hair is contrasted and the plain concrete solid, it is discovered that there is an expansion of $4.6 \%$ in compressive quality and 3\% in flexural quality. At the point when M-25 cement with $1.5 \%$ hair is contrasted and the plain concrete solid, it is discovered that there is an expansion of $11 \%$ compressive quality and $4 \%$ in flexural quality.(Jain \& Kothari, 2012) A study by Danso, Humphrey \& Manu, Dorothy reasons that the expansion of coconut strands and hydrated lime emphatically impacted the dirt concrete mortar properties as sturdy development material. It is, subsequently, suggested that $0.2 \%$ coconut fiber and $5 \%$ lime ought to be utilized by professionals to settled soil-concrete mortar for development applications. (Danso \& Manu, 2020). An examination indicated that the most extreme increment is in the expansion of $1.5 \%$ hair fiber, by weight of cement, in all the blends. (Sreevani \& Ajitha, 2017).

An exploration concentrates on the manufacture of concrete fiber blocks usage of $\mathrm{RH}, \mathrm{CB}$, and $\mathrm{CC}$ was finished by Abdullah, A C \& Lee, C C. In their work, it was discovered that CC has indicated the most potential filaments that influence the quality of the block delivered. In the interim, linseed oil shows the best treatment contrasted with the untreated, gelatin-hexamine blend, and sodium metasilicate-aluminumsulfate treatment. The strands after treated with 
linseed oil significantly affect quality, water ingestion, and a dimensional difference in blocks. In creating the CFB, fiber content likewise influenced the physical and mechanical properties. Ill-advised filaments substance will diminish the quality, water retention, and dimensional difference in CFB because of the conduct of characteristic fiber, which is hydrophilic. In this manner, it demonstrated that all the parameters above have a noteworthy job in creating a high quality of blocks and meet the structure measures for development. Although promising outcomes have been accounted for, future research is expected to completely comprehend the CFB's solidness. (Abdullah \& Lee, 2017)

From the investigation of S. Manivel et al. the ideal dose level of hair fiber expansion was seen as $2 \%$ while that of the substitution of GGBFS was seen as $20 \%$ by volume of cement. (Manivel et al., 2017). Quality and strength tests were led on hair fiber fortified cement by Manaf A. et al. further rmore, the outcomes show that there is an expansion in compressive quality by $12 \%$ and $22 \%$ expansion in flexural quality on the expansion of $1 \%$ hair fiber by weight of concrete. An expansion in flexural quality demonstrates the decrease in miniaturized scale breaks, which is a danger to solidness. The expansion of $1 \%$ hair fiber by weight of concrete shows better outcomes in quality when contrasted with different rates. Further expansion shows declination accordingly even though there is no misfortune not exactly the objective quality. (Manaf \& Varghese, 2017)

\section{METHODOLOGY}

As per Indian standards all the tests are being conducted according to the Indian standards. In this experimental study of concrete the different material taken has the following physical properties:

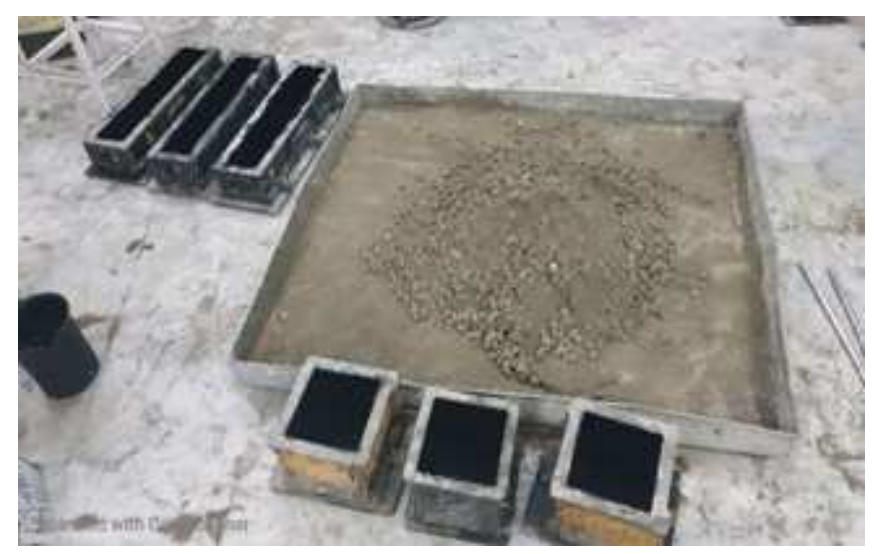

Figure 2: Material Mixing.

Table 1: Physical Properties

\begin{tabular}{|l|l|c|}
\hline \multirow{3}{*}{ Cement } & Fineness & $97.2 \%$ \\
\cline { 2 - 3 } & Specific gravity & 3.15 \\
\cline { 2 - 3 } & Compressive strength & $43 \mathrm{kN} / \mathrm{mm}^{2}$ \\
\hline \multirow{3}{*}{ Fine aggregate } & Fineness modulus & 3.2 \\
\cline { 2 - 3 } & Specific gravity & 2.6 \\
\cline { 2 - 3 } & Zone & $\mathrm{II}$ \\
\hline \multirow{2}{*}{ Coarse aggregate } & Fineness modulus & 7.6 \\
\cline { 2 - 3 } & Specific gravity & 2.67 \\
\hline Coconut coir & Specimen length & $6 \mathrm{~cm}$ \\
\hline Human hair & Specimen length & $6 \mathrm{~cm}$ \\
\hline
\end{tabular}


The human hair and coconut fibers are taken in the same proportion for the experimental study (i.e $1 \%$ fibers means .5\% human hair and $.5 \%$ coconut fibers) the concrete grade of M35 which is prepared by the ratio 1:1.6:2.9 gives the content or composition of the material as:

Table 2: Composition of Material

\begin{tabular}{|l|c|}
\hline Cement & $395 \mathrm{~kg} / \mathrm{m}^{3}$ \\
\hline Fine aggregate & $632 \mathrm{~kg} / \mathrm{m}^{3}$ \\
\hline Coarse aggregate & $1146 \mathrm{~kg} / \mathrm{m}^{3}$ \\
\hline Water & $198 \mathrm{~kg} / \mathrm{m}^{3}$ \\
\hline
\end{tabular}

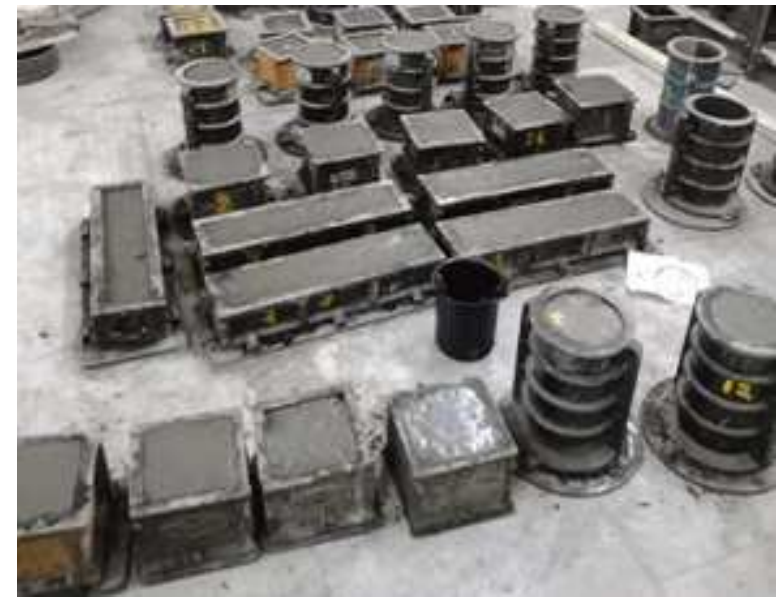

Figure 3: Casting of Concrete.

For the study of hardened properties of concrete three tests were carried out

1. Compressive strength test (150X150X150 mould)

$$
\text { Compressive Strength }=\frac{\text { Applied load in newton }}{\text { Area of contact of cube }}
$$

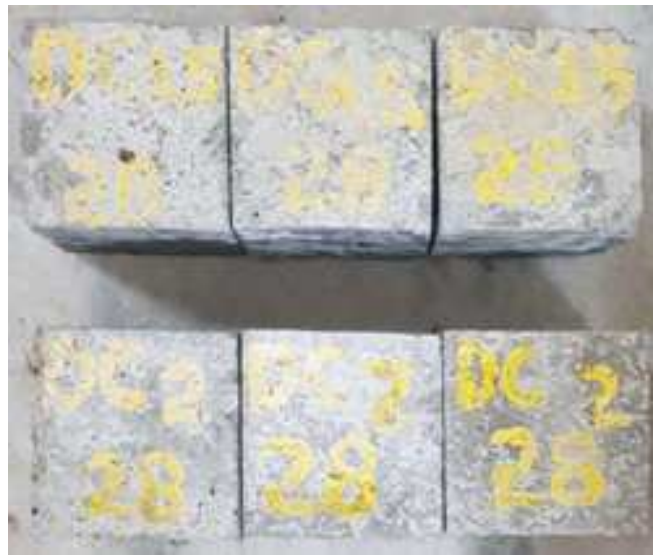

Figure 4: Cube Specimen for Compressive Test. 


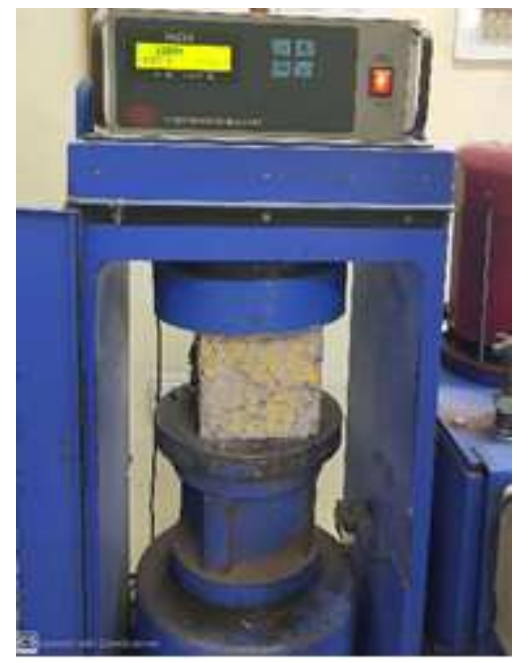

Figure 5: Compression Test of Cube.

2. Flexural Strength (100X100X 500 Moulds) flexural strength $=\frac{D L}{b d^{2}}$

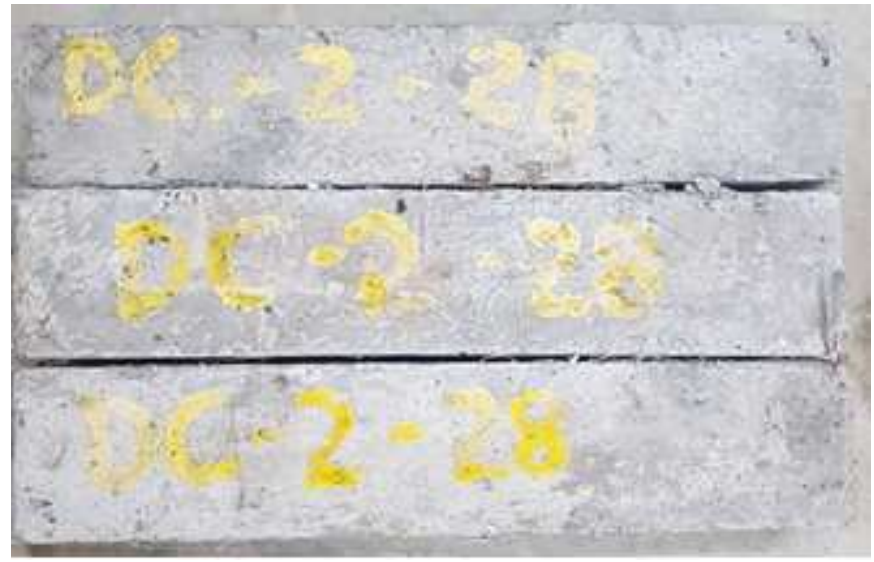

Figure 6: Beam Specimen for Flexure Test.

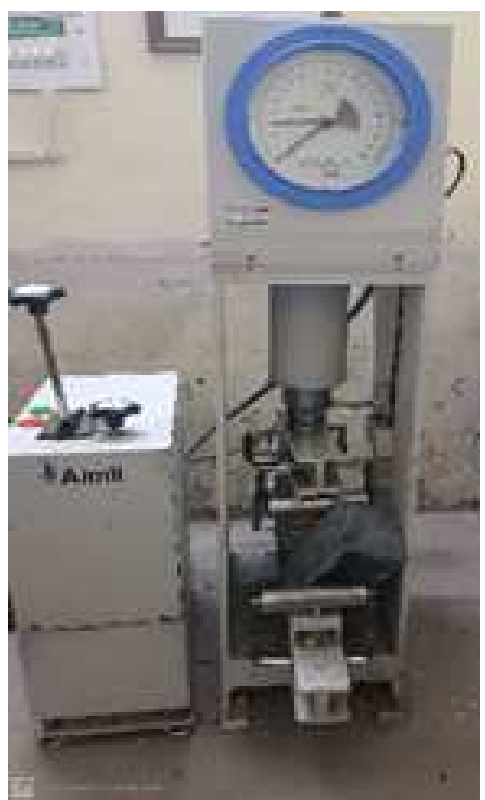

Figure 7: Flexure test of Beam. 
3. Split tensile strength (150X300 mould) Split tensile strength $=\frac{2 * l o a d}{\pi D L}$

The tests were performed according to the Indian standard provisions with room temperature $270 \mathrm{C}$ at the time of preparation of the specimen.

\section{RESULTS}

\section{Compressive Strength}

Table 1: Compressive Strength

\begin{tabular}{|c|c|c|c|}
\hline \multicolumn{4}{|c|}{ Compressive Strength } \\
\hline & 7 days & 14 Days & 28 Days \\
\hline Simple Concrete & 24.19 & 28.08 & 37.65 \\
\hline $1.0 \%$ Fibre & 22.58 & 25.67 & 34.19 \\
\hline $1.5 \%$ Fibre & 22.83 & 27.05 & 37.28 \\
\hline $2.0 \%$ Fibre & 19.15 & 20.61 & 28.45 \\
\hline
\end{tabular}

In this study it is mainly seen that when the combination of fibers introduced in the concrete section at $1 \%$ addition by the weight of cement, the result was somehow appreciable because the decrement of the strength was very less.

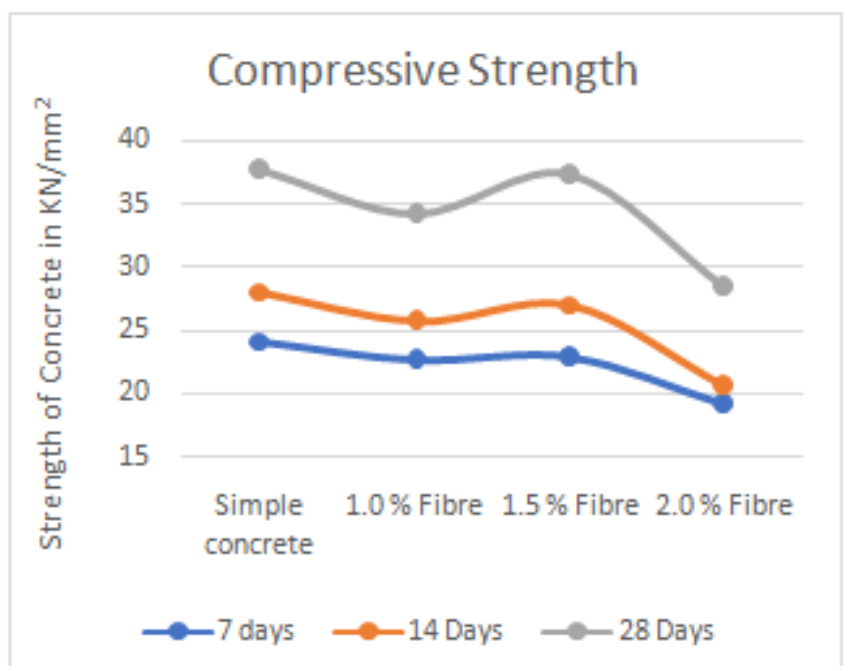

Figure 8: Compressive Strength of Concrete.

At $1.5 \%$ addition of a combination of fibers the strength of the concrete section increases, this is due to the compressive property of coconut coir fibers which increases in strength but at $2 \%$ addition the strength starts decreasing. This decrease in strength is due to the excess volume of fibers in the section which results in a decrease in strength.

\section{Flexure Strength}

Table 4: Flexural Strength

\begin{tabular}{|c|c|c|c|}
\hline \multicolumn{4}{|c|}{ Flexural Strength } \\
\hline & 7 days & 14 Days & 28 Days \\
\hline Simple concrete & 4.06 & 5 & 5.8 \\
\hline $1.0 \%$ Fibre & 3.33 & 4.48 & 6.53 \\
\hline $1.5 \%$ Fibre & 4.2 & 5.47 & 7.07 \\
\hline $2.0 \%$ Fibre & 2.93 & 3.86 & 4.8 \\
\hline
\end{tabular}




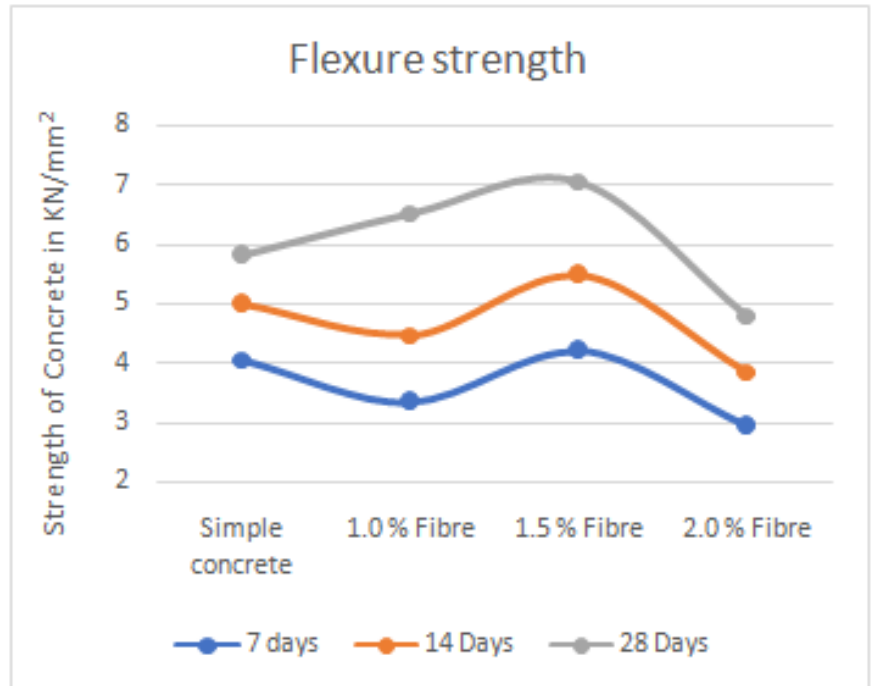

Figure 9: Flexure Strength of Concrete.

This composite study of concrete with human hair and coconut coir has optimum strength and maximum strength of flexural strength at $1.5 \%$ addition of fibers of the combination of human hair and coconut fiber in the same proportions. After that strength starts decreasing because the density of the coconut coir is very less and after the addition of $1.5 \%$ fibers by weight of cement, the volume of coconut fiber is high enough so there is no bond strength between concrete and fibers.

\section{Split Tensile Strength}

Table 5: Split Tensile Strength

\begin{tabular}{|c|c|c|c|}
\hline \multicolumn{4}{|c|}{ Split Tensile Strength } \\
\hline & 7 days & 14 Days & 28 Days \\
\hline Simple concrete & 2.4 & 2.8 & 3.7 \\
\hline $1.0 \%$ Fibre & 2.8 & 3.3 & 4.2 \\
\hline $1.5 \%$ Fibre & 3.3 & 3.5 & 4.5 \\
\hline $2.0 \%$ Fibre & 3.4 & 3.7 & 4.8 \\
\hline
\end{tabular}

As for the compressive strength and flexural strength, the optimum addition of fibers for split tensile strength was found to be also at $1.5 \%$. The reason for this is the same, because of the high volume of fibers in the section there is no bond creation between concrete and fiber. Another reason for the decrease in the strength is natural fiber absorbs water which results in slump decrease and this also affect the strength of the concrete section

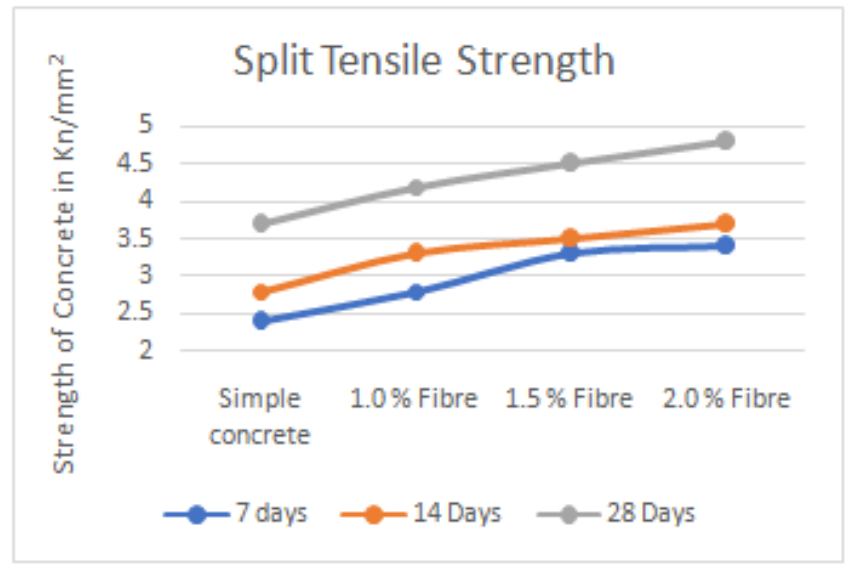

Figure 10: Split Tensile Strength of Concrete. 


\section{CONCLUSIONS}

- The concrete of M35 grade was prepared by the ratio 1:1.6:2.9.

- The optimum and maximum addition for compressive strength is $1.5 \%$ by the weight of cement. With very little change in compressive strength

- The optimum and maximum addition of fibers for flexural is $1.5 \%$ of cement weight. The increment of strength is $21 \%$.

- The optimum and maximum addition of fibers for Split tensile strength is $2 \%$ of cement weight. The increment of strength is $29 \%$.

- The high volume of fiber restricts the bond formation between concrete and fibers.

- The combination of human hair and coconut fiber was found to be good in an increase in the flexural and split tensile of the concrete.

- Due to the high volume of natural fibers i.e. coconut fiber the workability decreases because natural fibers absorb water.

\section{REFERENCES}

1. Abdullah, A. C., \& Lee, C. C. (2017). Effect of treatments on properties of cement-fiber bricks utilizing rice husk, corncob and coconut Coir. Procedia Engineering, 180, 1266-1273. https://doi.org/10.1016/j.proeng.2017.04.288

2. Ali, M., \& Chouw, N. (2013). Experimental investigations on coconut-fibre rope tensile strength and pullout from coconut fibre reinforced concrete. Construction and Building Materials, 41, 681-690. https://doi.org/10.1016/j.conbuildmat.2012.12.052

3. Auda, MIorpenda, M. J., Hou, Y., Balogun, M. B., Iliyasu, I., Umaru, S., Bansod, N. D., \& Jimoh, A. A. (2019). Microstructural evolution and hardness properties of coir-coconut husk powder reinforced polymer composites subjected to an acidic husk powder rein. Procedia Manufacturing, 35, 737-742. https://doi.org/10.1016/j.promfg.2019.06.017

4. Danso, H., \& Manu, D. (2020). Case Studies in Construction Materials In fl uence of coconut fi bres and lime on the properties of soil-cement mortar. Case Studies in Construction Materials, 12, e00316. https://doi.org/10.1016/j.cscm.2019.e00316

5. Darsana, P., Abraham, R., Joseph, A., Jasheela, A., \& Binuraj, P. R. (2016). Development of Coir-Fibre Cement Composite Roofing Tiles. Procedia Technology, 24, 169-178. https://doi.org/10.1016/j.protcy.2016.05.024

6. IS 456:2000. (2000). Plain and Reinforced Concrete - Code of Practice. Indian Standard, July.

7. IS 516:1959. (1959). Methods of Tests for Strength of Concrete. Indian Standard.

8. IS 5816:1999. (1999). Splitting Tensile Strength of Concrete- Method of Test. Indian Standard.

9. IS 9103:1999. (1999). Specification for Concrete Admixtures. Indian Standard, 1-22.

10. Jain, D., \& Kothari, A. (2012). Hair Fibre Reinforced Concrete. 1, 128-133.

11. Manaf, A., \& Varghese, G. M. (2017). Human Hair Fibre Reinforced Concrete. 6(03), 460-465. 
12. Manivel, S., Kumar, S. N., Prakashchandar, S., \& Kumar, S. A. (2017). Experimental Study on Human Hair Fiber Reinforced Concrete with Partial Replacement of Cement by. 8(4), 1145-1155.

13. Obada, D. O., Kuburi, L. S., Dauda, M., Iorpenda, M. J., Hou, Y., Balogun, M. B., Iliyasu, I., Umaru, S., Bansod, N. D., \& Jimoh, A. A. (2019). Microstructural evolution and hardness properties of coir-coconut husk powder reinforced polymer composites subjected to an acidic husk powder reinforced polymer composites subjected to an acidic environment environment. Procedia Manufacturing, 35, 737-742. https://doi.org/10.1016/j.promfg.2019.06.017

14. Roy, S. Sen, \& Balling, R. C. (2004). Trends in extreme daily precipitation indices in India. International Journal of Climatology, 24(4), 457-466. https://doi.org/10.1002/joc.995

15. Sathiparan, N., Nishanthana, M., \& Pavithra, B. H. M. (2017). Performance of coconut coir reinforced hydraulic cement mortar for surface plastering application. Construction and Building Materials, 142, 23-30. https://doi.org/10.1016/j.conbuildmat.2017.03.058

16. Sreevani, G., \& Ajitha, S. B. (2017). Human Hair as Fibre Reinforcement in Concrete. 7(5), 11358-11364.

17. Kumar, Duppala Ajay Kumar \& C H Bharath. "Processing and Mechanical Behaviour of Human Hair Fiber Reinforced Polymer Composites." International Journal of Mechanical and Production Engineering Research and Development (IJMPERD) 8.5 (2018):107-116

18. Naveen, P. N. E., and R. V. Prasad. "Evaluation of Mechanical Properties of Coconut Coir/Bamboo Fiber Reinforced Polymer Matrix Composites." International Journal of Metallurgical \& Materials Science and Engineering (IJMMSE) 3.4 (2013): 1522.

19. Salleh, Mmbh, et al. "Mechanical Properties of Coconut Carbon Fibre/Epoxy Composite Material." International Journal of Mechanical Engineering (IJME) 2.3 (2013):55-62

20. Oleiwi, Jawad K., Sihama I. Salih, and Hwazen S. Fadhil. "Water Absorption and Thermal properties of PMMA Reinforced by Natural Fibers for Denture Applications." International Journal of Mechanical and Production Engineering Research and Development (IJMPERD) 8.3 (2018): 1105-1116.

21. Aziz, Omar Q., and Bahman O. Taha. "Mechanical properties of high strength concrete (HSC) with and without chopped carbon fiber (CCF)." International journal of civil engineering (IJCE), 2.1 (2013): 1-12.

22. Sandhu, Rajindervir Singh, Jaspal Singh, and Gurpreet Singh Dhanoa. "Effect of Air Cooled Blast Furnace Slag and Polypropylene Fibre on Mechanical Properties of Concrete." International Journal of Civil, Structural, Environmental and Infrastructure Engineering Research and Development [IJCSEIERD] 5.3 (2015): 45-56. 

